\title{
Mid-pregnancy ewe shearing and the effects on fetus liver and muscle glycoprotein deposits
}

\author{
João Carlos Morini Junior ${ }^{1}$, Adriana Caroprezo Morini ${ }^{2}$, Lina Castelo Branco Motta ${ }^{1, \mathfrak{z}}$, \\ Carlos Eduardo Ambrosio ${ }^{3}$, Phelipe Oliveira Favaron ${ }^{1}$, Flávia Thomaz Verechia Rodrigues ${ }^{4}$, Luiz Alberto \\ Oliveira Ribeiro ${ }^{5}$, Luciana Relly Bertolini ${ }^{6}$, Marcelo Bertolini ${ }^{5}$, Maria Angélica Miglino ${ }^{1}$, \\ Pedro Primo Bombonato ${ }^{1}$
}

\author{
${ }^{1}$ Faculty of Veterinary Medicine and Animal Science, São Paulo University, São Paulo, Brazil. \\ ${ }^{2}$ Federal University of West of Pará, Santarem, Pará, Brazil. \\ ${ }^{3}$ Faculty of Animal Science and food Engineering, São Paulo University, Pirassununga, São Paulo, Brazil. \\ ${ }^{4}$ Paulista State University, Dracena, São Paulo, Brazil. \\ ${ }^{5}$ Federal University of Rio Grande do Sul, Rio Grande do Sul, Brazil. \\ ${ }^{6}$ University of Fortaleza, Ceará, Brazil.
}

\begin{abstract}
The reason why shearing ewes in midpregnancy does increase the lamb birth weight is not completely clears. Therefore, we focused on the analyses of the deposition of glycogen in different fetal tissues to investigate this issue. Thirteen pregnant Australian Merino ewes, raised in native pasture, were separated in two groups. One group $(n=7)$ was shorn (SE) at 70 days of pregnancy, whereas another group $(n=6)$ remained unshorn (NSE). Cesarean section was conducted in all the ewes at near parturition, when placenta and fetuses sampling were collected. Placenta, liver and muscle samples were fixed and stained with glycoproteinreactive acid-Schiff acid for analysis under light microscopy. The quantification of these glycoproteins was performed with the support of a program that analyzes the measurement of the intensity of staining by field. Five random fields from each sample were used, where statistical analyzes was used as normal test $\mathrm{T}$. Among the analyzed regions, the deposition of glycoprotein between SE and NSE groups was statistically different in the hepatic portal vein $\left(54,499.23 \mu \mathrm{m}^{2}\right.$ in SE and $34,830.73 \mu \mathrm{m}^{2}$ in NSE) and in the total muscle area of the sample fragment $\left(41,128,7 \mu \mathrm{m}^{2}\right.$ and $31,942.7 \mu \mathrm{m}^{2}$, respectively; $\left.\mathrm{P}<0.05\right)$. We conclude that shearing ewes at the 70th day of gestation lead to accumulation of glycoproteins in the liver and muscle of fetuses, which may be responsible for the increase in birth weights in that group.
\end{abstract}

Keywords: bone, glycoprotein, lamb, muscle, placenta.

\section{Introduction}

The sheep farming has high social and economic importance, since it is an agricultural activity that originates various products such as meat, dairy products, wool and leather. However, a problem faced by this industry is reproductive losses, represented by high mortality rates of newborns (Dwyer et al., 2006).

Adverse climatic conditions and low birth weight are the main causes of death of lambs in the perinatal period (Labeur et al., 2017; Godfrey et al., 2017; Elizalde et al., 2018). In cold regions, the condition tends to worsen, since low body weight may cause hypothermia, since lambs after birth do not have enough surface area to perform heat exchange, besides having low energy reserves to control their temperature (McCoard et al., 2014). It was verified that the shearing of sheep during pregnancy causes the birth of lambs of greater body weight (Morris and Mccutcheon, 1997). Lauber et al. (2017) have found that lambs born to ewes shorn in late-pregnancy are better able to maintain body surface temperature than those derived from unshorn ewes. However, the cause for such an event is not completely clear. Decades ago, some authors have associated such event to placental factors. Since placental growth is completed around the 90th day of pregnancy, shearing on day 70 could change the maternal metabolism, leading to an increase in glucose supply to the uterus and, consequently, to the fetus (Alexander, 1964; Symonds et al., 1986). Such change could be responsible for an increase in placental size enhance and fetal weight.

Based on that, this work aimed to evaluate whether shearing pregnant ewes would have any effect on fetal liver and muscle glycoprotein deposits (GAD).

\section{Material and methods}

All procedures were approved by the Bioethics Commission of the Faculty of Veterinary Medicine and Animal Science of the São Paulo University, $\mathrm{n}^{\mathrm{o}}$ $1157 / 2007$

A flock of 21 Australian Merino ewes were raised under native pasture of the Brazilian Lutheran University, located in the state of Rio Grande do Sul, Brazil. Mating was carried out by two ram, the day of mating being considered as day zero. After 15 weeks, ultrasound examinations were performed, confirming positive pregnancy in 13 ewes, all with single fetus. These ewes were divided into two groups: the first $(n=7)$ was shorn (SE) with 70 days gestation, while the second $(\mathrm{n}=6)$ remain unshorn (NSE). Near the period of parturition, around 140 days of gestation in relation to the day of each mating, the cesarean sections were performed in all the ewes, where the placenta and the fetuses were collected.

Fetuses and placentas were weighed, and fragments of the fetal left Rectus femoris muscle, liver and samples of placentomes (both the maternal - caruncle 
- as well as the fetal - cotyledon) were collected. Samples were cut and reduced tot the size of $1 \mathrm{~cm}$. Then, fragments were fixed in Bouin alcohol, with either $4 \%$ parafomoldehyde or $10 \%$ formaldehyde, both made in sodium phosphate buffer (PBS).

After fixation, samples were washed in PBS, dehydrated in an ethanol series of increasing concentration (70 to $100 \%$ ), to be diaphanizated in xylol and included in paraplast. Sections of $5 \mu \mathrm{m}$ were made using a microtome (Leica - RM2065, Berlim Germany). To analyze a larger area of the fragments at different locations in each block cut out material follows five sequential sections were produced subsequently kept the blades cut from 100 microns to produce more and we returned five sequential slides this method is repeated in each block 3 times

The slides for morphological description for placenta tissue were stained with hematoxylin-eosin (HE) and analyzed under light microscopy. The technique of periodic acid-Schiff (PAS) for histochemistry reaction was used to visualize the accumulation of glycoproteins.

To assess the amount of glycoprotein in the slides stained with PAS, five fields of $50 \mu \mathrm{m}^{2}$ per animal were measured, with $40 \mathrm{x}$ of magnification. These fields were uniform and from different histological sections of each sample. The image of each field was obtained through an Axioscopie Zeiss ${ }^{\circledR}$ optical microscope and analyzed in a microcomputer with a specific program for morphometry (Kontron KS4003.0 ), which allows the measurement of the glycoprotein through the difference in color intensity in the different regions of the field analyzed. The color intensity was measured from the intensity of the reaction of PAS with glycoprotein, therefore, areas with greater amount of glycoproteins were marked more strongly. Selecting the region stained with PAS in each of the fields it is possible to obtain an average value of color intensity, consequently, the quantity of glycogen present in that area. (Fig. 1).

In the placentomas, the glycoproteins were analyzed in the villi and endometrial glands, besides the vessels, epithelium and mesenchyme, both maternal and fetal. In the liver tissue, the analyzed areas were the portal triad, portal vein, center lobular vein, sinusoids and hepatocytes, whereas on the muscle tissue, fibers, vessels and fat tissue were evaluated. In the rectus femoris muscle, the analysis of the disposition of the muscular fibers between the groups was performed, besides the deposition of glycoproteins in fragments of the muscular vessels and the adipose cells of the muscles.

The results were presented descriptively with mean \pm standard deviation (SD). The normality of the data was verified by the Kolmogorov-Smirnov test, adopting for the analysis of the means of the groups the test $\mathrm{T}$, being performed with the RGui version 2.6 program (R-project, University of Auckland, New Zealand), with the significance level of 5\%.

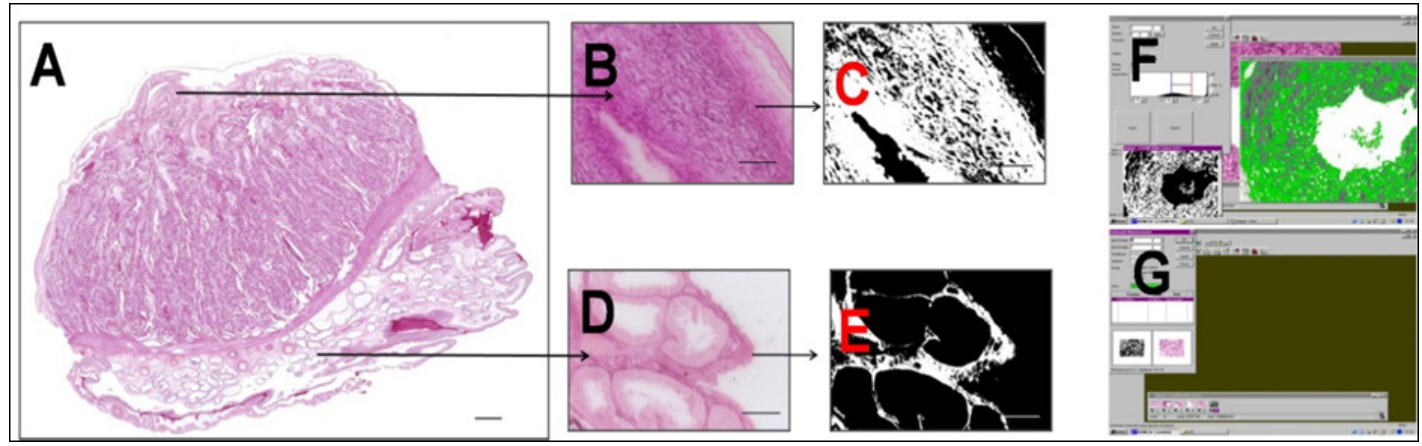

Figure 1. Used methodology for glycogen deposit evaluation. A: Ovine placentome, PAS, $200 \mu \mathrm{m}$; B and D are examples of random measured areas that were analyzed, PAS, $25 \mu \mathrm{m}$; C and E were quantified areas in white after phase contrast image; $25 \mu \mathrm{m} ; \mathrm{F}$ and $\mathrm{G}$ are examples of the specific program for area measurement.

\section{Results}

The mean weights of the fetuses were $3,688 \mathrm{~kg}$ in the SE group and $3,596 \mathrm{~kg}$ in the NSE group, while the average placental weights were $2,287 \mathrm{~kg}$ and $1,923 \mathrm{~kg}$, respectively. Despite the difference in body and placental weights between the groups, these values were not statistically significant $(\mathrm{P}>0.05)$.

The placentones, both in the maternal and fetal regions, presented a simple cubic epithelium (Fig. 2), rich in vessels in the connective tissue (Fig. 3C) with villi on both sides (Fig. 3A). The placental endometrial glands were provided with simple cubic epithelium surrounded by connective tissue (Fig. 3B). All other analyzed fields of the placenta had higher deposition of glycoprotein in sheared group, but without statistical differences between the groups, as shown in Table 1 .

The livers of the fetuses derived from both groups had characteristic structural composition, with central lobular veins, sinusoidal capillaries, and hepatocytes in the parenchyma (Fig. 4C and 4D). In the portal triad, more specifically in the hepatic portal vein, glycoprotein quantified in the SE group was significantly higher than in the NSE group (Tab. 2). Like the portal vein, another site where a significant statistical difference between the groups was noted was the Rectus femoris muscle in its total area, where the SE group had a higher deposition of glycoprotein in comparison to the fetal muscle of the group NSE, as shown in Table 2. The muscle fibers and adipocytes found in both groups had similar composition (Fig. 4A and 4B). 

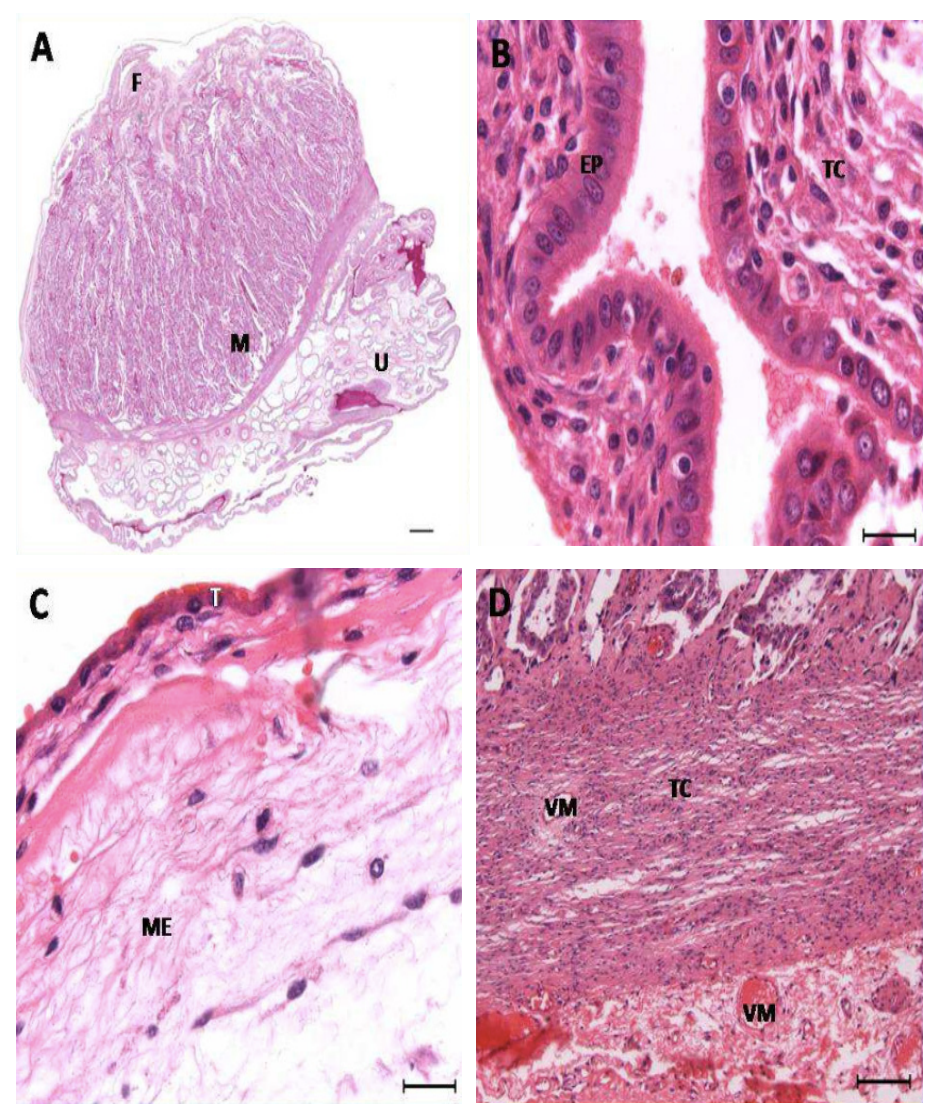

Figure 2. Photomicrographs of the areas studied in ovine placentones. A: panoramic view of the placentome of sheep stained by PAS; B: maternal epithelium stained by HE; C: fetal epithelium stained by HE; D: maternal connective tissue. F: fetal margin; M: maternal margin; U: uterine margin; EP: uterine epithelium; TC: connective tissue; T: trophoblast; ME: mesenchyme; VM: maternal vessel. Bar A: $500 \mu \mathrm{m}$; B and C: $20 \mu \mathrm{m}$; D: $100 \mu \mathrm{m}$.
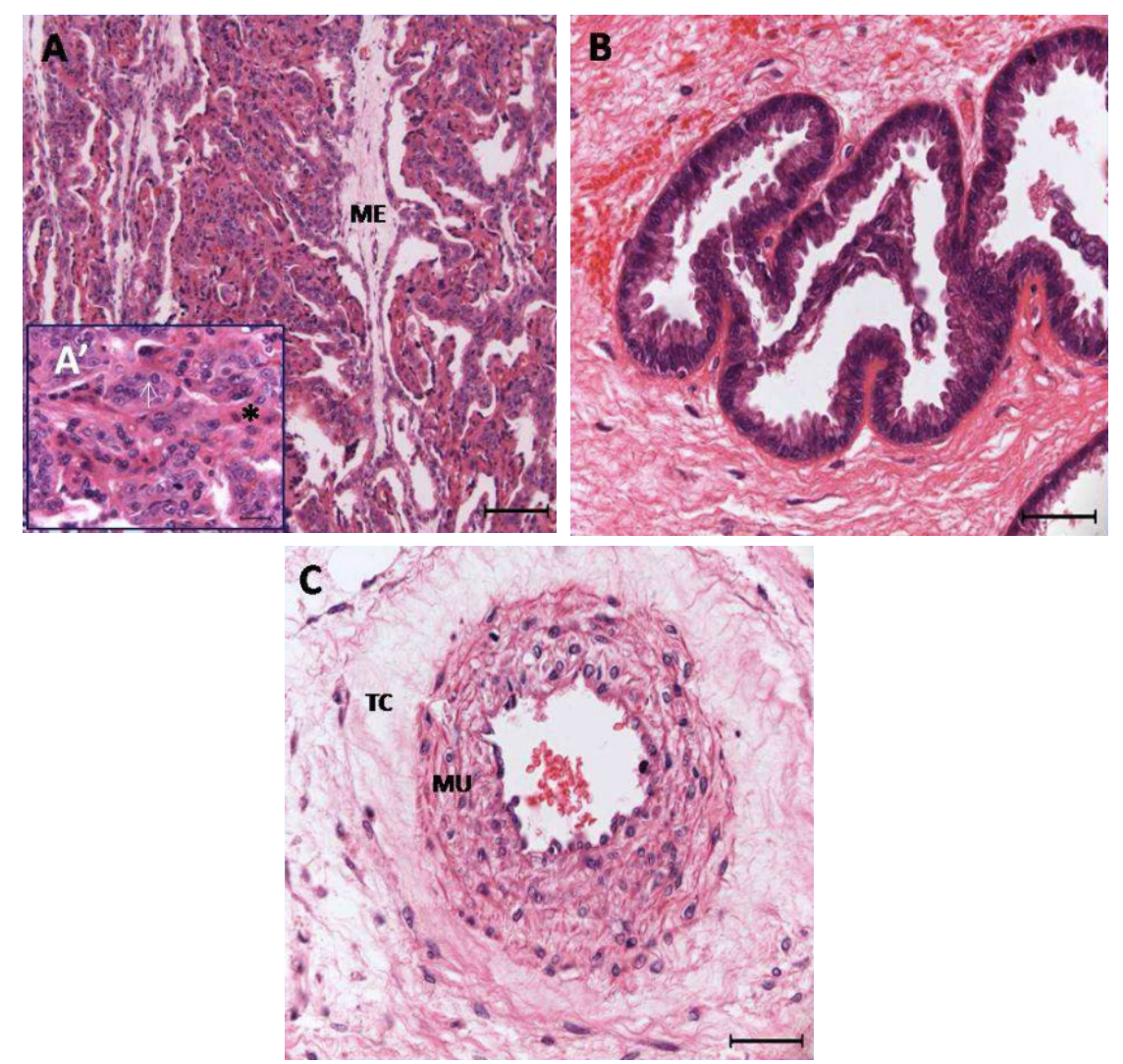

Figure 3. Photomicrographs of the areas studied in sheep placentones. A: placentomial villi; A': maternal and fetal part of villus; B: endometrial glands; G: fetal muscular artery. ME: mesenchyme; arrow-fetal villus; * maternal villus; TC: connective tissue; MU: muscular. Stained with HE. Bar A: $100 \mu \mathrm{m} ; \mathrm{A}^{\prime}: 20 \mu \mathrm{m}$; B and C: $40 \mu \mathrm{m}$. 
Table 1. Average of the GAT area $\left(\mu \mathrm{m}^{2}\right)$ found in placenta between the groups shorn at $70^{\text {th }}$ day of gestation (SE) and unshorn pregnant ewe (NSE).

\begin{tabular}{lcll}
\hline & & SE & NSE \\
\hline Vessel & (M) & $36131 \pm 4416^{\mathrm{a}}$ & $38740 \pm 8075,4^{\mathrm{a}}$ \\
Epithelium & (F) & $46076 \pm 17972,3^{\mathrm{a}}$ & $45304 \pm 9034,9^{\mathrm{a}}$ \\
& (M) & $28067 \pm 10929,5^{\mathrm{a}}$ & $24841 \pm 5971,5^{\mathrm{a}}$ \\
Mesenchyme & (F) & $35634 \pm 18102^{\mathrm{a}}$ & $23435 \pm 262,1^{\mathrm{a}}$ \\
& $(\mathrm{M})$ & $43459 \pm 16849,9^{\mathrm{a}}$ & $33675 \pm 6583,7^{\mathrm{a}}$ \\
Vilosities & (F) & $40863 \pm 18729,2^{\mathrm{a}}$ & $30412 \pm 7862,8^{\mathrm{a}}$ \\
Endometrial glands & & $41682 \pm 13210,2^{\mathrm{a}}$ & $35636 \pm 12521,1^{\mathrm{a}}$ \\
\hline
\end{tabular}

*P $\leq 0.05$; averages with distinct letters on lines are different by significance by $\mathrm{T}$ student statistical test. M: maternal part; F: fetal part.
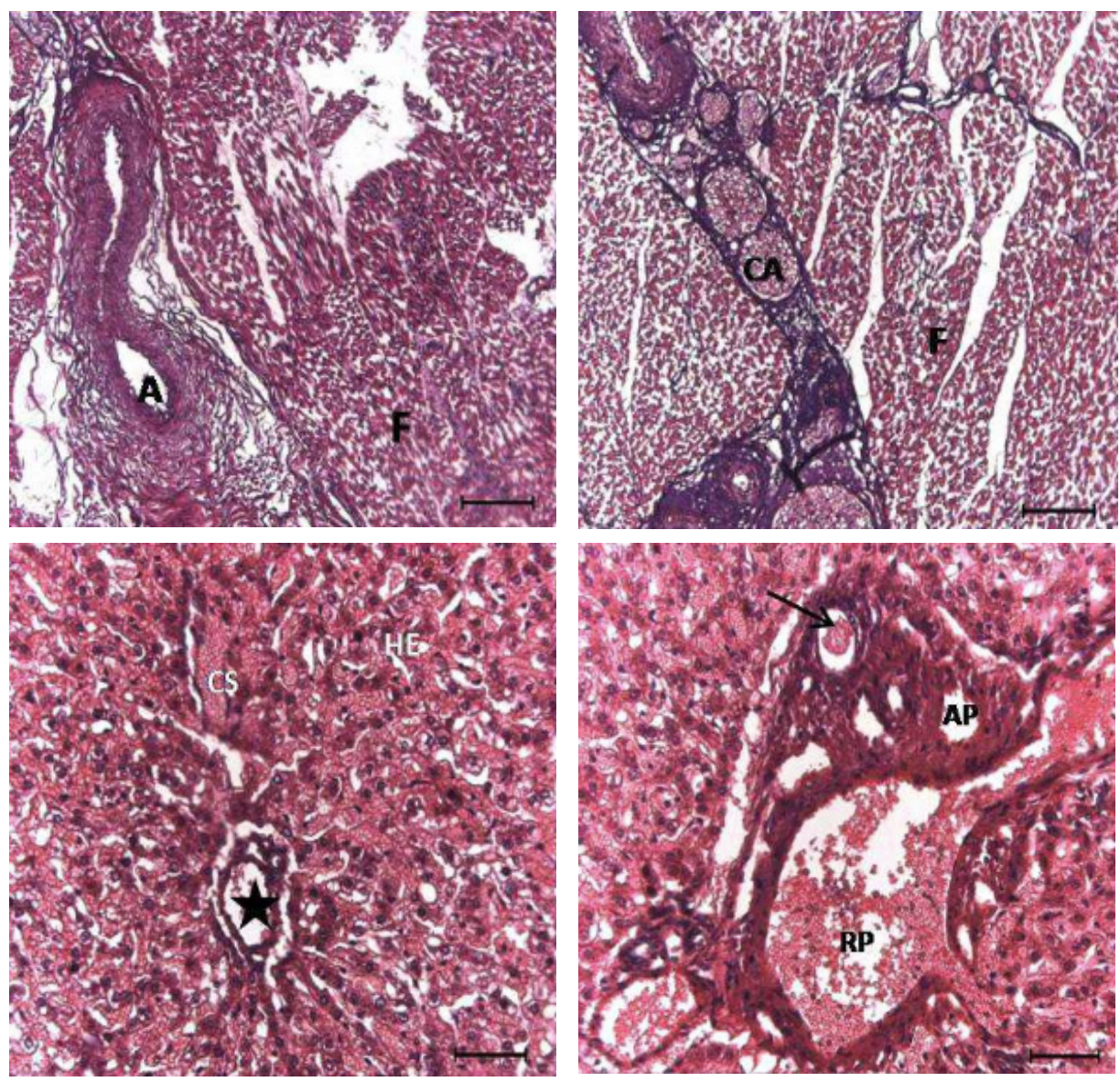

Figure 4: Photomicrographs of the areas studied in the ovine muscle (A and B) and liver (C and D). A: elastic artery; B: adipocyte cells; C: lobular center vein, sinusoid capillary; D: portal triad. A (black): elastic artery; CA: adipocyte cells; CS: sinusoidal capillary; F: muscle fiber; HE: hepatocytes; star: lobular center vein; arrow: bile duct; AP: hepatic artery; VP: portal vein. Stained by HE. Bar A and B: $100 \mu \mathrm{m} ; \mathrm{C}$ and D: $50 \mu \mathrm{m}$.

Table 2. Results (Average, Max and Min) of GAT in liver portal vein area and Rectus femoris muscle area $\left(\mu \mathrm{m}^{2}\right)$ of fetus from pregnant ewe shorn at $70^{\text {th }}$ day of gestation (SE) and unshorn pregnant ewe (NSE).

\begin{tabular}{lcccc}
\hline & \multicolumn{3}{c}{ Liver portal vein } & \multicolumn{2}{c}{ Fetal Rectus femoris muscle } \\
\cline { 2 - 5 } & SE & NSE & SE & NSE \\
\hline Average & $54499 \pm 3020,9^{\mathrm{a}}$ & $34831 \pm 6470,5^{\mathrm{b}}$ & $41129 \pm 1715,7^{\mathrm{a}}$ & $31943 \pm 4054^{\mathrm{b}}$ \\
Max & 58419 & 39526 & 42737 & 37509 \\
Min & 51026 & 25681 & 38751 & 27970 \\
\hline
\end{tabular}

$* \mathrm{P} \leq 0.05$; averages with distinct letters on lines are different by significance by $\mathrm{T}$ student statistical test. 


\section{Discussion}

Thermal stress is a common problem in sheep farming (Godfrey et al., 2017). Survival capacity is intertwined with the lamb's response to the environment in which it is born (Dwyer et al, 2006). It is often found in cold climatic conditions, where the lamb has a low percentage of body fat in relation to its surface area, which increases heat loss (McCoard et al., 2014), also causing differences in metabolic rates, consequently in the available energy reserves (caused by the tremors) (Labeur et al., 2017). The shearing of sheep during gestation has been commonly used as an alternative because it is capable of altering the placental metabolism (Black et al., 1990), consequently the body weight of lambs (Ribeiro et al., 2010). However, the motive responsible for this fact is not fully understood.

When analyzing the levels of glycoproteins, we found that they were in a higher concentration in the SE group, thus suggesting that they may be responsible for the increase in body weight. The concentration range of glycoproteins analyzed in our study indicates that the glycoproteins accumulate in the fetus during gestation and may be directly related to the stress caused by shearing during the gestational period, because Roussel et al. (2004) verified the increase of cortisol in lambs with higher body weight. Barbieri et al. (2018) found that there is an increase in placental weight and the number of cotyledons in sheared sheep in the middle of pregnancy, which may increase levels of nutrient transfer between the sheep and the fetus. Supporting the hypothesis of this author, in the present study, the placental weight of the sheared group was higher, that is, the fetal weight may be being increased by the increase of nutrient transfers, consequently, of glycoproteins. Guyoti et al. (2015) also verified that sheep shearing affected the hematological parameters of the lambs, hematocrine and hemoglobin values being lower in shear groups. This author cited that the greater amounts of hematocrine in lambs derived from nonsheared sheep may have occurred as a compensatory effect of decreased blood distribution to the fetus, consequently the resulting hypoxia may lead to less placental growth.

Among the structures studied in the liver, the portal vein showed significant differences between SE and NSE groups. That vessel carries $80 \%$ of the blood to the liver, consisting of little amount of oxygen, but rich in nutrients (Junqueira and Carneiro 2004). The nutrients may be responsible for the significant difference in the amounts of glycoprotein between groups. Since during gut absorption the liver captures and converts glucose into glycoprotein and triglycerides (Cunningham, 1999) and as the shearing protocol results in an increase in fetal weight (Morris and McCuttheon, 1997; Banchero et al., 2010; Guyoti et al., 2015; Barbieri et al., 2018), it is highly possible that shearing in our study was associated with higher concentration of glycoprotein in the liver of fetuses from shorn ewes.

In the fetal Rectus femoris muscles in the SE group, large amounts of glycoprotein were found, being significantly different from the control group. This significance may be related to the development of the fetus. According to Toboga et al. (2003), the glycoprotein is metabolized quickly as needed when it is required, and when the fetus is larger, it needs a higher demand of glycoprotein.

Insulin is the ideal substance because it is the physiological regulators, exerting a number of simultaneous effects on interconnected metabolic pathways (Wiernsperger, 2005). The reduced insulin secretion may have reduced glucose utilization by maternal tissues, thus sparing glucose for use by the placental/fetal unit (Revell et al., 2000). In Wiernsperger (2005), it was suggested that the reduced insulin response to glucose challenge, alternatively, may have been due to an increased sensitivity of maternal tissues to insulin such that less quantities was required to clear the glucose load. Consequently, the insulin challenges caused the same reductions in plasma glucose concentrations in all ewes studied, which did not support the concept of altered insulin sensitivity. The non-insulin dependent uptake of glucose across the placenta is an important factor described in the literature as a likely candidate to account for a more rapid glucose clearance from the maternal circulation (Revell et al., 2000). The author suggested that the facilitated diffusion of glucose across the placenta was enhanced by shearing in mid-pregnancy, leading to an increase in the maternal-fetal gradient in glucose concentration, which would normally be associated with an increase in maternal glucose concentration.

A number of studies have showed that the midpregnancy shearing resulted in increase in the birth weight of both singleton and twin lambs. Corner et al. (2007) showed that increases in lamb birth weight have generally been reported in either singleton (Morris et al., 2000; Kenyon et al., 2002; Revell et al., 2002) or twin-born lambs (Morris and McCutcheon, 1997; Smeaton et al., 2000; Kenyon et al., 2004), but less frequently for both (Kenyon et al., 2002; Corner et al., 2006). According to results obtained by Revell et al. (2000), the shearing protocol results in an increase of over $1.0 \mathrm{~kg}$ in the mean birth weight of twin lambs in response to mid-pregnancy shearing, without any change in the birth weight of singletons. Revell et al. (2002) showed that the increase in lamb birth weight was due, in part, to an increase in gestation length of 1.2 days. Shearing ewes during pregnancy resulted in an increased gestation length of approximately 1 day. These results indicate that mid-pregnancy shearing can increase lamb birth weight without increasing ewe herbage intake or placental weight. An increase in the efficiency of nutrient uptake by the placenta is implied, and possible effects on the activity of thermogenic tissues are discussed. The placental weight as well as the study of Revell et al. (2002) was also higher in the clipped traces showing that glycoproteins and nutrient uptake and transported through the placenta to the fetus may be responsible for the weight gain of the fetus at birth.

Alternatively, shearing during mid-pregnancy has also been shown not to alter the proportion of lambs born weighing less than $3.5 \mathrm{~kg}$ (Corner et al., 2007). 
The author suggested that mid-pregnancy shearing did not alter the fetal growth rate of small lambs. Some similar information was described by Guyot et al. (2015). However, Kenyon et al. (2006) reported midpregnancy shearing to result in an increase in the survival rate of twin and triplet lambs due to a reduction in the proportion of lambs that weighed less than $3.5 \mathrm{~kg}$ at birth, which is economically important to the sheep industry. Despite the small difference of 100 grams in weight of the media made between the groups in our work, we work with lambs at 6 pounds, close to the results presented in the work of Corner et al. (2007), although none of our animals have reached the final stage of pregnancy and rising off the weight was quite close to the findings of this author, both in late pregnancy in which he found in the middle of gestation was $3.5 \mathrm{~kg}$ and next to our work. Thus agreeing with the findings of the Kenyon et al. (2006) shearing performed during pregnancy causes increase in birth weight of lambs. We cannot say that the differences found in glycoprotein deposition levels are the only ones responsible for the increase in fetal weight, but we can say that there is an accumulation of these in body fat, thus making the lamb heavier.

In conclusion, after studying the deposits of glycoproteins in placental and fetal tissues of shorn and unshorn Australian Merino ewes on day 70 of gestation, but the concentration of glycoproteins it is increased in sheared groups. The largest concentration of glycoprotein in the liver fetal occured around the fetal blood vessels, more specifically in the pericyte branches of the hepatic portal vein. Lambs born from ewes shorn on day 70th of pregnancy showed a higher deposition of muscle glycoprotein. The difference in concentration of fetal liver glycoprotein in the muscle and femoral tissue of lambs, confirms the hypothesis that shearing ewes on day 70 of pregnancy increases birth weight.

\section{Acknowledgments}

The authors wish to thank the Brazilian Institutes CNPq, CAPES, and FAPESP for financial support.

\section{References}

Alexander G. 1964. Studies on the placenta of the sheep (Ovis aries l.). J Reprod Fertil, 7:289-305.

Banchero G, Vázquez $A$, Montossi F, Barbieri I, Quintans G. 2010. Pre-partum shearing of ewes under pastoral conditions improves the early vigour of both single and twin lambs. Anim Prod Sci, 50:309-314.

Barbieri ID, Montossi F, Vinoles C, Kenyon. 2018. Time of shearing the ewe not only affects lamb live weight and survival at birth and weaning, but also ewe wool production and quality. New Zeal J Agr Res, 61:57-66.

Black HJ, Chestnutt DMB. 1990. Influence of shearing regime and grass silage quality on the performance of pregnant ewes. Anim Prod, 51:573-582.

Corner RA, Keynon PR, Stafford JK, West DM, Oliver MH. 2006. The effect of mid-pregnancy shearing or yarding stress on ewe post-natal behaviour and the birth weight and post-natal behaviour of their lambs. Livest Sci, 102:121-129.

Corner RA, Keynin PR. Stafford KJ, West DM, Oliver MH. 2007. The effect of mid-pregnancy shearing and litter size on lamb birth weight and postnatal plasma cortisol response. Small Rumin Res, 73:115-121.

Cunningham JG. 1999. Tratado de fisiologia veterinária. 2ed. Rio de Janeiro: Guanabara Koogan. 304:291-299.

Dwyer CM, Morgan CA. 2006. Maintence of body temperature in the neonatal lamb: Effects of breed birth weight, and litter size. J Anim Sci, 84:1093-1101.

Elizalde HF, Carson AF, Munõz C. 2018. Effects of sire genotype on lamb performance at weaning in extensive sheep systems. Animal, 1-8. doi: 10.1017/S1751731118000848.

Godfrey RW, Preston WD, Joseph SR, LaPlace L, Hillman PE, Gebremedhin KG, Lee CN, Collier RJ. 2017. Evaluating the impact of breed, pregnancy, and hair coat on body temperature and sweating rate of hair sheep ewes in the tropics. J Anim Sci, 95:2936-2942.

Guyoti VM, Farias MS, Dalmolin ML, Plo CH, Schmidt V, Gonzalez FD. 2015. Effect of shearing during pregnancy on productive performance in the post-partum period of ewes on extensive husbandry. Ciênc Anim Bras, 16:217-224.

Junqueira LC, Carneiro J. 2004. Histologia básica. 10ed. Rio de Janeiro: Guanabara Koogan. 488p.

Kenyon PR, Revell DK, Morris ST. 2002. Midpregnancy shearing can increase birthweight and survival to weaning of multiple-born lambs under commercial conditions. Aust J Exp Agr, 46:821-825.

Kenyon PR, Morel PCH, Morris ST. 2004. Effect of liveweight and condition score of ewes at mating, and shearing mid-pregnancy, on birthweights and growth rates of twin lambs to weaning. $N Z$ Vet $J, 52: 145-149$.

Kenyon PR, Sherlock RG, Parkinson TJ, Morris ST. 2006. The effect of maternal shearing and thyroid hormone treatments in mid pregnancy on the birth weight, follicle, and wool characteristics of lambs. New Zeal J Agr Res, 48:293-300.

Labeur L, Villiers G, Small AH, Hinch GN, Schomelzl S. 2017. Infrared thermal imaging as a method to evaluate heat loss in newborn lambs. Res Vet Sci, 115:517-522.

McCoard SA, Henederson HV, Knol FW, Dowling SK, Webster JR. 2014. Infrared thermal imaging as a method to study thermogenesis $\mathrm{n}$ the neonatal lamb. Anim Prod Sci, 54:1497-1501.

Morris ST, Mccutcheon SN. 1997. Selective enhancement of growth in twin fetuses by shearing ewes in early gestation. Anim Sci, 65:105-110.

Morris ST, Mcuthcheon SN, Revell DK. 2000. Birth weight responses to shearing ewes in early to mid gestation. Anim Sci, 70:363-369.

Revell DK, Main SF, Breier BH, Cottam YH, Hennies M, Mccutheon SN. 2000. Metabolic responses to mid-pregnancy shearing that are associated with a selective increase in the birth weight of twin lambs. Domest Anim Endocrinol, 18:409-422. 
Revell DK, Morris ST, Cottam YH, Hanna JE, Thomas DG, Brown S, Mccutcheon SN. 2002. Shearing ewes at mid-pregnancy is associated with changes in fetal growth and development. Aust J Agric Res, 53:697-705.

Ribeiro LAO, Brito MA, Mattos RC. 2010. Ewes shorn and unshorn during pregnancy in South Brasil: effects on body condition score and lamb birth weight. Braz J Vet Res Anim, 47:111-117.

Roussel S, Hemsworth PH, Boissy A, Duvaux-Ponter C. 2004. Effects of repeated stress during pregnancy in ewes on the behavioural and physiological responses to stressful events and birth weight of their offspring. Appl Anim Behav Sci, 85:259-276.

Smeaton DC, Bown MD, Clayton JB. 2000. Optimum liveweight, feed intake, reproduction, and calf output in beef cows on North Island hill country, New Zealand. New Zeal J Agr Res, 43:71-82.

Symonds ME, Bryant MJ, Lomax MA. 1986. The effect of shearing on the energy metabolism of the pregnant ewe. Brit J Nutr, 56:635-643.

Toboga SR, Romanelli PF, Felisbino SL, Borges LF. 2003. Acompanhamento das alterações post-mortem (glicólise) no músculo do jacaré do pantanal (Caiman crocodilus yacare). Ciên Tecnol Aliment, 22:70-75.

Wiernspenger NF. 2005. Is non-insulin dependent glucose uptake a therapeutic alternative? Part 1: physiology, mechanisms and role of non insulindependent glucose uptake in type 2 diabetes. Diabetes Metab, 31:415-426. 